\title{
System of Satellite Monitoring of Spring Snowmelt in Kazakhstan
}

\author{
Alexey G. Terekhov, Nikolay G. Makarenko \\ Institute of Information and Computational Technologies, Almaty, Kazakhstan \\ aterekhov1@yandex.ru
}

\begin{abstract}
Daily NASA product MOD10L2 (snow fraction) and product Snow Depth (USGS/EROS FEWS NET) were used for estimation of snow state in Kazakhstan during 2001-2018 years. The season's monitoring included 61 days, from March 1 to April 30, for MOD10L2 and 120 days, from Juanuary 1 to April 30, for Snow Depth. Each year was characterized by maps of the seasonal maximum snow depth (absolute and relative scales) and calendar dates of spring snowmelt with two separate maps of the snow-line position on March 18-22 and March 29-April 3. This information makes it possible to evaluate the degree of proximity of the 2018 year with previous ones (20012017). The 2018 year was extremely without snowy with low expected volumes of spring flood.
\end{abstract}

Keywords: remote sensing, satellite data, snow fraction, snow depth, snow cover, map of calendar dates of spring snowmelt, map of seasonal maximum snow depth, spring flood

Copyright (C2019 by the paper's authors. Copying permitted for private and academic purposes 


\title{
СИСТЕМА СПУТНИКОВОГО МОНИТОРИНГА ПРОЦЕССОВ ВЕСЕННЕГО СНЕГОТАЯНИЯ В КАЗАХСТАНЕ
}

\author{
А.Г. Терехов, Н.Г. Макаренко \\ Институт информационных и вычислительных технологий МОН, Алматы, Казахстан \\ aterekhov1@yandex.ru
}

\begin{abstract}
Ежедневные продукты NASA MOD10L2 («snow fraction») и Snow Depth (USGS/EROS FEWS NET) использовались для оценки состояния снежного покрова Казахстана в сезонах 2001-2018 годов. Период сезонного мониторинга включал 61 день, с 1 марта по 30 апреля, для MOD10L2 и 120 дней, с 1 января по 30 апреля, для Snow Depth. Каждый год характеризовался картами сезонного максимума высоты снега (абсолютная и относительная шкала), а также суммарной картой темпов весенного снеготаяния, с двумя отдельными картами позиций снеговой линии на 18-22 марта и 29 марта - 3 апреля. Эта информация давала возможность оценить степень близости режима 2018 года к прошлым годам (2001-2017 гг.). Сезон 2018 года оказался исключительно малоснежным, с низкими ожидаемыми объемами весеннего половодья.
\end{abstract}

Ключевые слова: дистанционное зондирование, спутниковые данные, доля покрытия снегом, высота снега, снежный покров, карта календарных дат весеннего снеготаяния, карта сезонного максимума высоты снега, весеннее половодье

\section{Введение}

Около 40\% годовых осадков в равнинной части территории Казахстана выпадает в холодный период в виде снега. Весеннее снеготаяние в Казахстане часто сопровождается разрушительными паводками. Накопленные за холодный период запасы снега являются важным источником влаги для богарного земледелия и весеннего половодья рек. Также запас снега этого периода формирует запасы воды в гляциальных зонах формирования стока. Вододефицитный, резко континентальный климат Казахстана характеризуются значительной сезонной вариативностью условий увлажнения. Это проявляется: в объёмах весеннего половодья [1]; в значительных изменениях спектральных характеристик земель, в связи с реакцией растительности на уровень почвенного увлажения [2]; а также в вариациях годовых объемов стока рек снежно-ледового питания [3]. Спутниковый мониторинг над процессами весеннего снеготаяния на территории Казахстана несёт важную информацию об особенностях погодного режима и объёмах зимнего снегонакопления. Темпы освобождения территории от снега в весенний период зависят от количества накопленого зимой снега и погодных условий периода снеготаяния. Решение некоторых, практически востребованных задач, таких как, оценка: дат снеготаяния; запасов снега; активности паводковых явлений; может упрощаться с помощью 
информации, полученной при анализе спутниковых карт распределения снежного покрова в отдельные временные периоды и их сравнении с прошлыми сезонами (2001-2017 гг.). Появляется возможность выбрать из архива условия наиболее близкие к текущему сезону и на этой основе оценивать виды на активность весенних паводков, предпосевные объёмы запасов воды в почве на богарной пашне Северного Казахстана и в гляциальной зоне формирования стока.

\section{Цель работы}

Целью работы являлось создание набора обзорных карт по состоянию снежного покрова на территории Казахстана в течение последних 18 лет (2001-2018 гг.) и сравнение режима весны 2018 года с прошлыми годами (2001-2017 гг.). Карты расположения снеговой линии и высоты снежного покрова Казахстана в шкале абсолютных и относительных значений дают основу для сопоставления режима текущего года с прошлыми сезонами. На основе этой информации можно рассматривать некоторые прикладные аспекты, в том числе, искать «год аналог», в котором динамика разрушения снежного покрова была бы максимально близка к сценарию 2018 года. Соответственно, паводковая активность, весенние запасы продуктивной влаги в почве и в гляциальной зоне формирования стока «года аналога» могут служить в качестве ориентира на текущий сезон.

\section{Территория мониторинга}

В работе рассматривалась территория Казахстана. При описании весеннего снеготаяния наиболее информативны равнинные части Республики, где наблюдается выраженная пространственная и временная динамика изменений в расположениях снеговой линии и высоты снежного покрова. Динамика весеннего снеготаяния и запаса снега в горных территориях Казахстана требует отдельного, регионального рассмотрения.

\section{Используемая спутниковая информация}

В настоящий момент спутниковая информация широко используется для пространственновременной характеристики снежного покрова Земли. В свободном доступе находится ряд спутниковых продуктов, которые предоставляет «National Snow and Ice Data Center» [http://nsidc.org/data], Finnish Meteorological Institute [http://www.globsnow.info], COPERNICUS EC [https://www.copernicus.eu], USGS/EROS FEWS NET [https://earlywarning.usgs.gov/fews]. В данной работе использовались суточные продукты MOD10L2 collection 6 (снежный покров) от NSIDC и Daily Snow Depth (толщина снежного покрова) от USGS/EROS FEWS NET. Время доступа к актуальной спутниковой информации у этих продуктов обычно составляет от одного до трёх дней, что обеспечивает приемлимую оперативность оценок.

\section{Методика обработки спутниковой информация}

Суточные продукты MOD10L2 collection 6 (снежный покров) [4,5] и Daily Snow Depth (высота снежного покрова) [6,7] имеют архив данных с 2001 года. Это обстоятельство позволяет формировать обзорные карты пространственного распределения снежного покрова с 1 марта по 30 апреля за последние 18 лет. Ключевыми периодами для межсезонного сравнения карт продукта MOD10L2 (снежный покров) были выбраны 18-22 марта и 31 марта - 3 апреля. Это давало прогнозный горизонт до начала активного снеготаяния, примерно, в 20 и 10 дней. 
Диапазон времени накопления (4 - 5 дней) обусловлен необходимостью строить временные композиты для уменьшения экранирующего влияния облачного покрова [8]. Информация по доле покрытия территории снегом (0-100\%) внутри пикселя продукта MOD10L2 имеет ограниченную ценность. Свежевыпавший снег, фактически, огрубляет регистрируемую картину до 2-х классов подстилающей поверхности, снежный покров $(100 \%)$ и безснежная зона $(0 \%)$. Поэтому, при обработки сцен MOD10L2 также применялся такой бинарный подход. Выделялась территория имеющая снежный покров (не важно с какой проективной величиной) и открытые, безснежные территории. Формирование временных композитов производилось путём удаления изображений территорий находящихся под облачным покровом и замена их соответствующими фрагментами со сцен с предшествующей датой. И так до тех пор, пока не сформируется вся безоблачная территория или не исчерпается временной архив сцен MOD10L2. Архива из 5-6 суточных сцен (18-22 марта и 29 марта-3 апреля), как правило, не хватает для формирования полностью безоблачных покрытий, но доля безоблачной территории при этом становится достаточно велика, чтобы можно было проводить сравнения между различными годами. Для продукта USGS/EROS FEWS NET «Daily Snow Depth (высота снежного покрова)» использовался период мониторинга с 1 января до окончания снеготаяния на равнинной части Казахстана, что обычно происходит к 30 апреля. Для каждого годового сезона из имеющегося 4-х месячного мониторинга над распределением снега по высоте выбирался один день с максимальными запасами в среднем для Казахстана (сезонный максимум). Эти карты служили характеристикой в пространственной структуре распределения запасов снега на территории Казахстана для выбранного сезона. Для сравнения сезонов различных лет карты пространственного распреления снега по толщине пересчитывались в индекс условий, по аналогии с растительностью [9]. Из 17 карт годовых максимумов снега (2001-2017 гг.) в каждой пиксельной позиции опрелялась зарегистрированная минимальная и максимальная высота снега. Полученная шкала рекалибровалась в условные единицы. Минимум принимался за 0, максимум за 100. Значения конкретных сезонов пересчитывались согласно линейной апроксимации в числа в пределах от 0 до 100.

\section{Полученные результаты и их обсуждение}

Карты пространственного распределения снежного покрова на территории Казахстана в ключевые временные периоды (18-22 марта и 29 марта - 3 апреля) в течение 2001-2018 годов по данным MOD10L2 представлены на рисунках 1,2. На рисунке 3 показаны обзорные карты календарных дат весеннего снеготаяния для всего периода мониторинга 2001-2018 гг. На рисунках 4-6 продемонстрированы результаты мониторинга и обработки данных по высоте снежного покрова Казахстана в период с 1 января по 30 апреля в сезонах с 2001 по 2018 гг., продукт Snow Depth USGS/EROS FEWS NET.

Суточный продукт MOD10L2 (снежный покров) с архивом с 2001 года дает основу для оценок конфигураций снеговой линии текущего сезона, ее временной эволюции в процессе весеннего снеготаяния. Эта информация позволяет получать оценки темпов снеготаяния, определять ранняя или поздняя весна, а также ее особенности в различных регионах Казахстана. Для сезона 2018 года темпы схода снега были близки к средним многолетним условиям, без выраженных аномалий в отдельных регионах. Суточный продукт Snow Depth USGS/EROS FEWS NET с архивом с 2001 года даёт информацию по запасам снега, в формате высоты снежного покрова. Таким образом, значительно повышается информативность спутниковой диагностики состояния снежного покрова. Кроме пространственного распределения есть характеристики по его количеству. Одним из важных параметров при формировании весеннего половодья и оценок запасов влаги в почве является водный эквивалент снега, который тесно связан с толщиной снежного покрова [10]. Рассматривая сезон 2018 года по параметру высота снежного покрова, можно отметить его исключительно низкую снежность. Год являлся наиболее малоснежным за весь имеющийся период спутникового мониторинга (2001-2018 гг.). Таким образом, снежный покров Казахстана в весенний период 2018 года отличался относительно малой величиной водного эквивалента, но по темпам снеготаяния, был близок к средним многолетним условиям. В аспекте ожидаемой активности весеннего половодья, такой режим не предполагает 
формирования больших объемов весенних паводков от таяния снега. Но остаются потенциальные угрозы паводков, вызванных значительными осадками в отдельные дни периода снеготаяния.

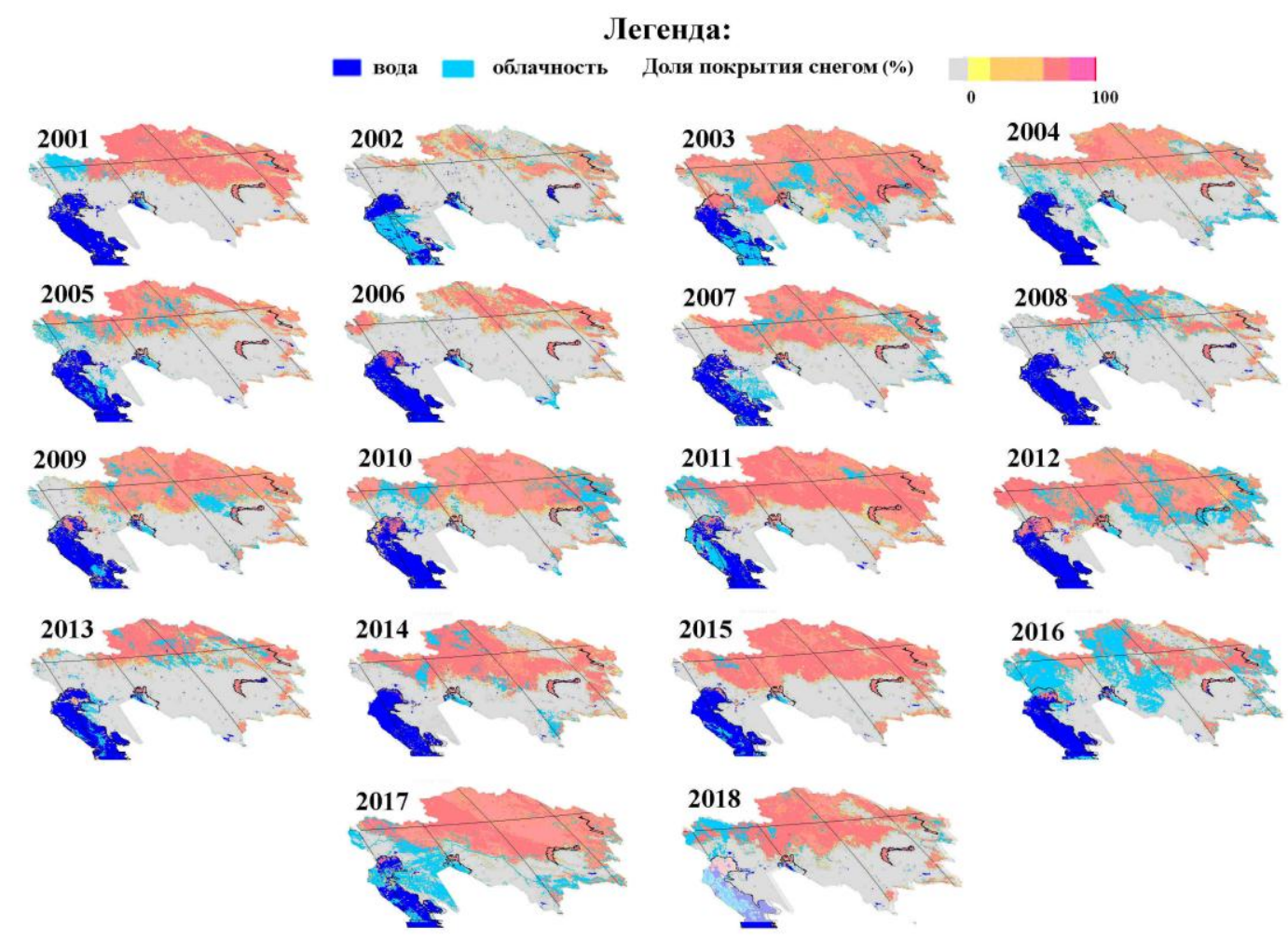

Puc. 1. Карты снежного покрытия территории Казахстана на 18-22 марта в сезонах 2001-2018 годов. Построено по спутниковым данным MOD10L2 (collection 6)
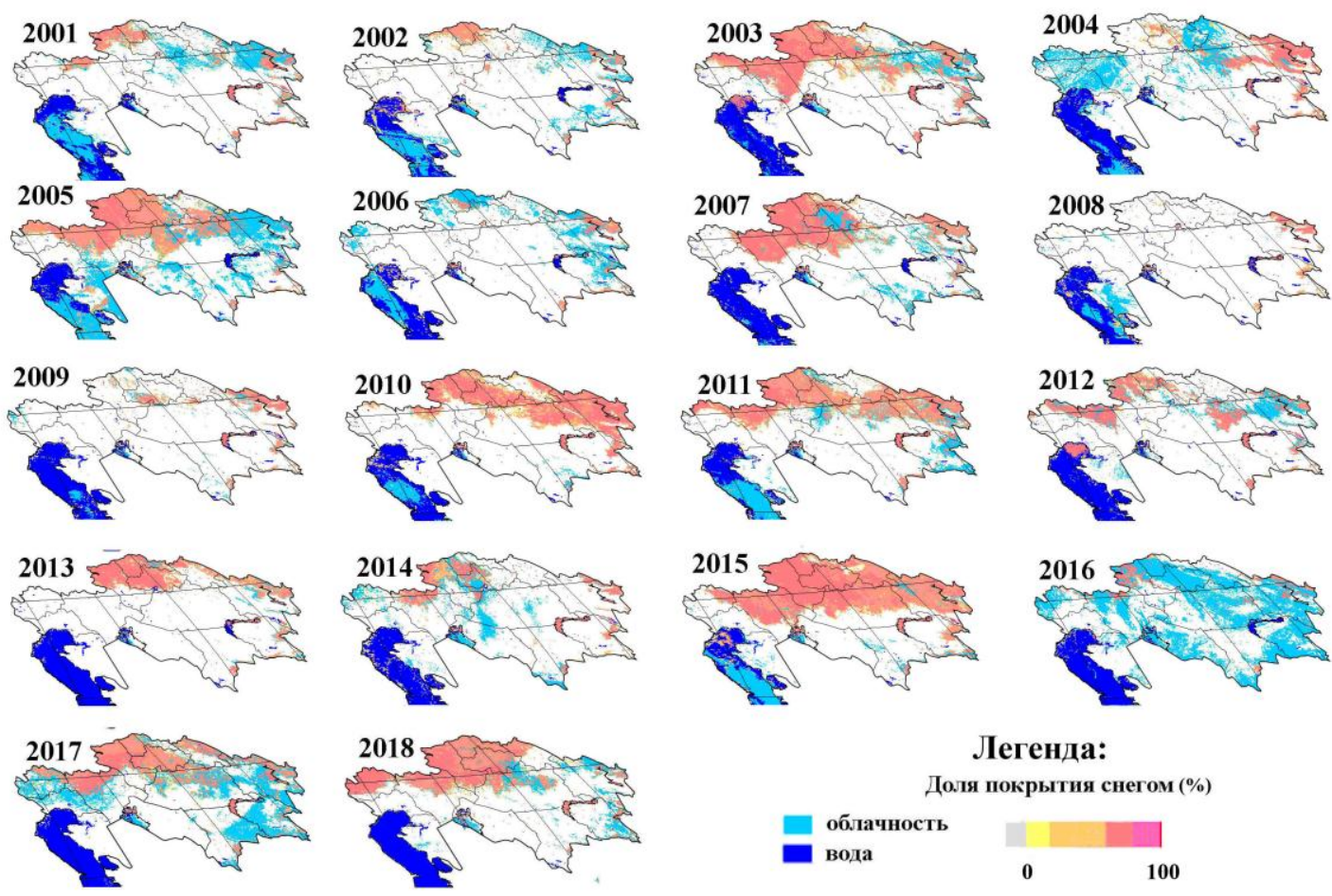

Puc. 2. Карты снежного покрытия территории Казахстана на 29 марта- 3 апреля в сезонах 2001-2018 годов. Построено по спутниковым данным MOD10L2(collection 6) 

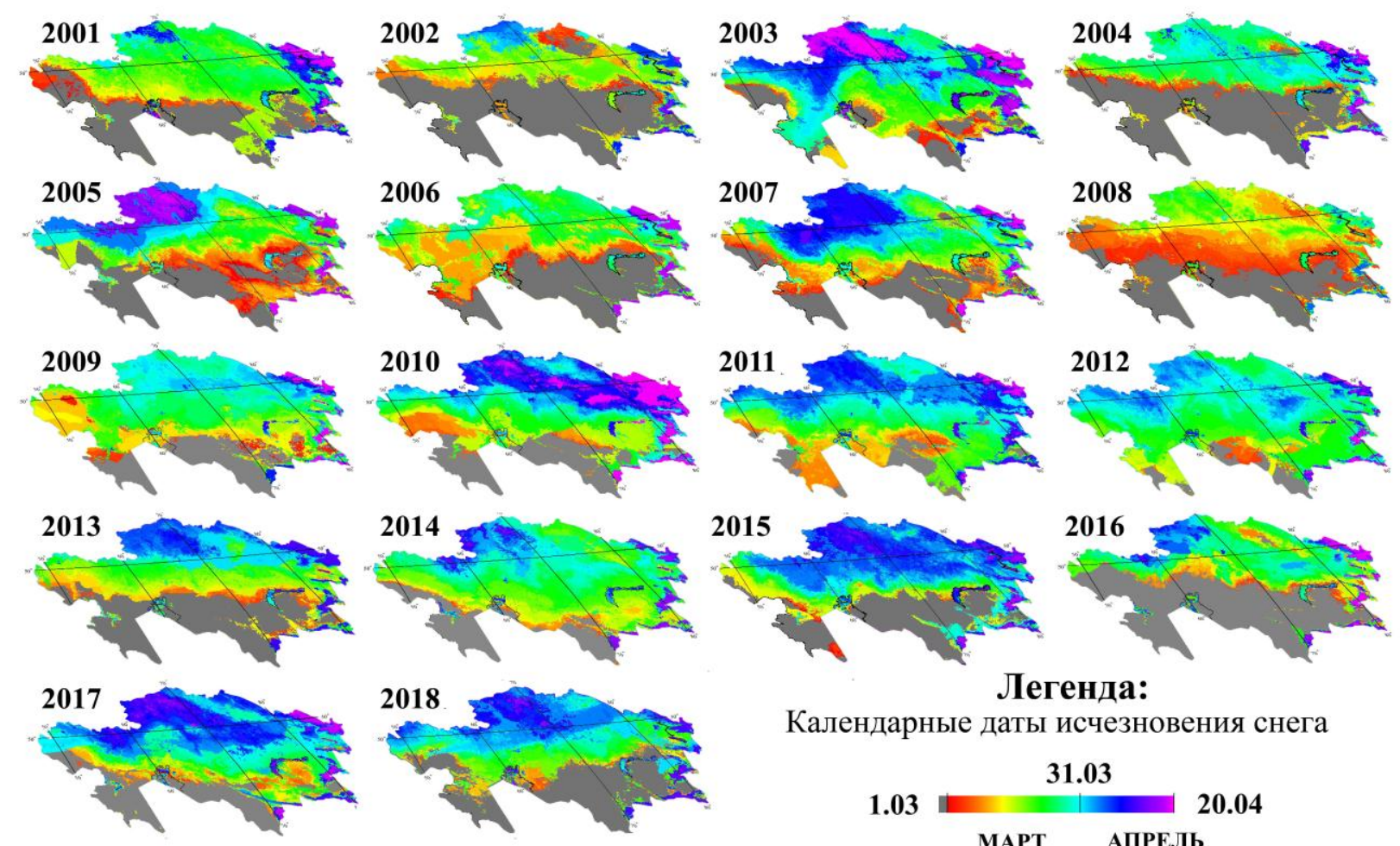

\section{Легенда:}

Календарные даты исчезновения снега

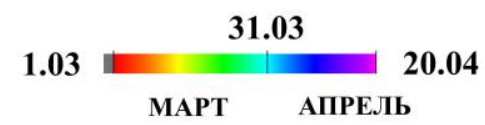

Pис. 3.Обзорные карты календарных дат весеннего снеготаяния в сезонах 2001-2018 гг. Построено на основе спутниковых данных MOD10L (collection 6)

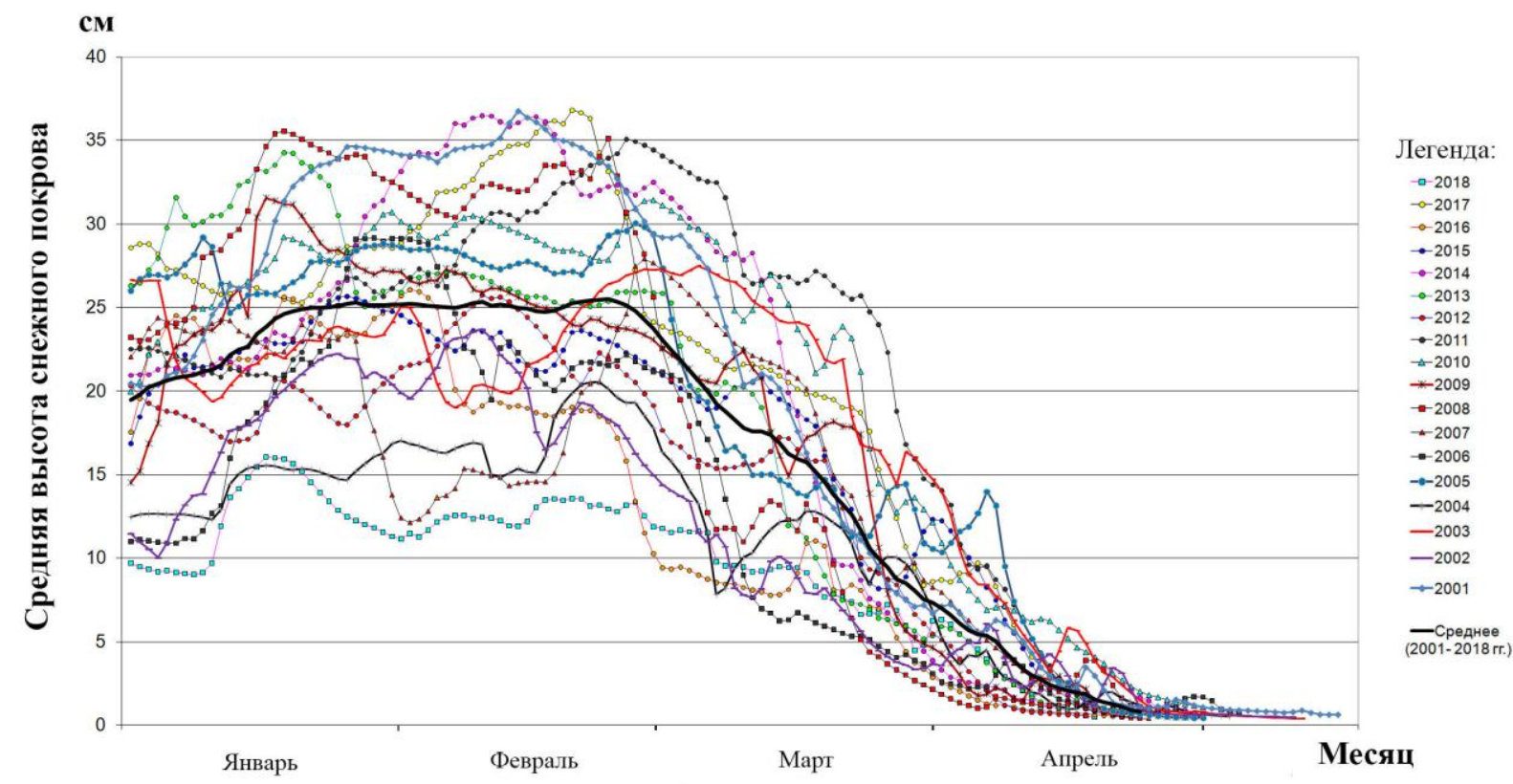

Puc. 4. Динамика средней высоты снежного покрова на территории Казахстана в период с 1 января до 30 апреля в сезонах 2001-2018 гг. Построено на основе спутникового продукта Snow Depth (USGS/EROS FEWS NET) 

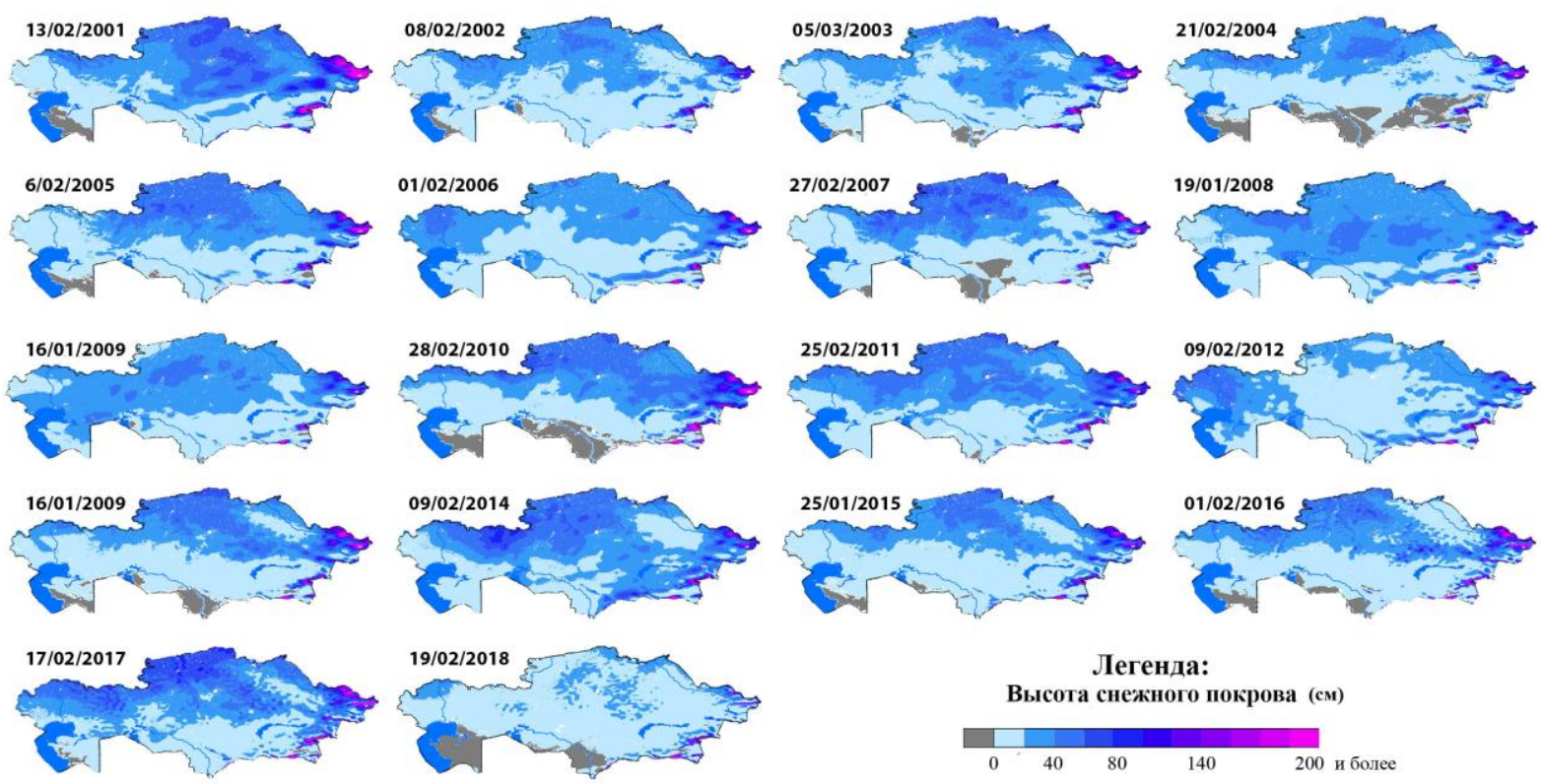

Легенда:

Высота снежного покрова (см)

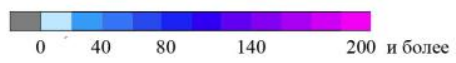

Puc. 5. Обзорные карты высоты снежного покрова Казахстана (сезонные максимумы) для периода 2001 2018 годов. Спутниковый продукт - Snow Depth (USGS/EROS FEWS NET)

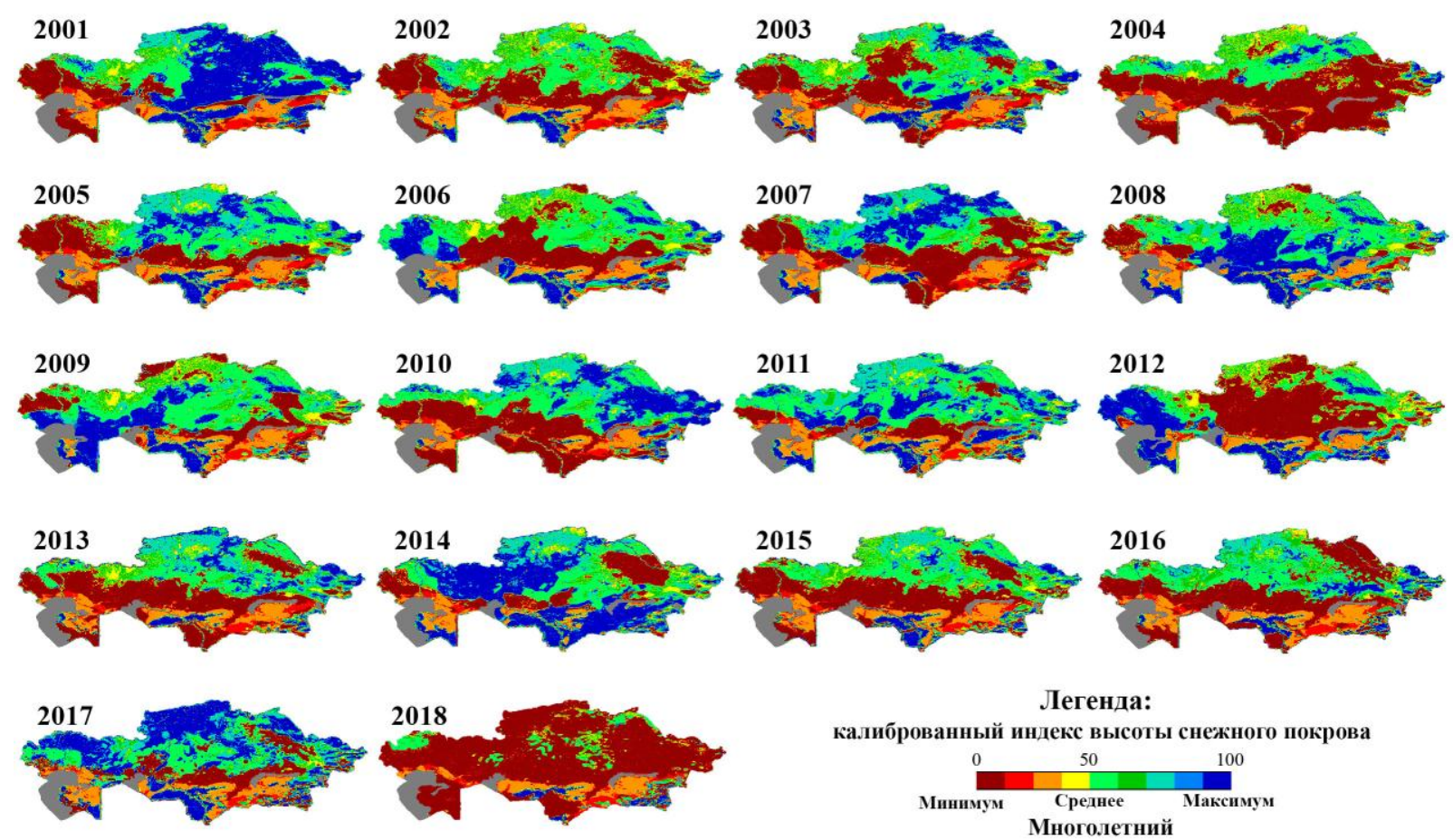

Puc. 6. Обзорные карты высоты снежного покрова (сезонные максимумы) Казахстана в относительной шкале для сезонов 2001-2018 гг. Построено на основе спутникового продукта Snow Depth (USGS/EROS FEWS NET) 


\section{Выводы}

Спутниковый мониторинг параметров снежного покрова равнинной части Казахстана по позиции снеговой линии - продукт MOD10L2; и по высоте снега - продукт Snow Depth USGS/EROS; позволяет, используя 18-летний архив суточных данных, характеризовать текущий сезон. Абсолютные и относительные оценки дают возможность определять «год аналог», как наиболее близкий по количеству снега (высота снега) и темпам снеготаяния, из имеющего архива данных (2001-2018 гг.). Для 2018 года «год аналог» отсутствовал, что было вызвано аномально низкой снежностью сезона в Казахстане. Разработанная система спутникового мониторинга снежного покрова имеет практический интерес в качестве дополнительного инструмента в системе прогноза активности весеннего половодья, оценке запасов воды в почве в начале вегетационного сезона и в гляциальной зоне формирования стока. Работа выполнена при финансовой поддержке министерства образования и науки Республики Казахстан, гранты № AP05134227, AP05134241.

\section{References}

[1] Terekhov A.G., Pak I.T., Dolgikh S.A., Satellite observation of the anomalous spring flood at the lower reach of the Ayagus River in 2016, Sovremennye problemy distantsionnogo zondirovaniya Zemli iz kosmosa, 2016, 13(4), pp. 273-277. DOI: 10.21046/2070-7401-2016-13-18-273-276. (In Russian).

[2] Spivak L., Vitkovskaya I., Batyrbayeva M., Terekhov A., The experience of land cover change detection by satellite data, Frontiers of Earth Science, 2012, 6(2), pp. 140-146. DOI: 10.1007/S11707-012-0317-Z.

[3] Terekhov A.G., Pak I.T., Dolgikh S.A., Hydrology monitoring of Kapchagay Reservoir on River Tekes (China's part of River Ile basin) based on LANDSAT 5,7,8 data and DEM batymetry, Sovremennye problemy distantsionnogo zondirovaniya Zemli iz kosmosa, 2015, 12(6), pp. 174-182. (In Russian).

[4] Salomonson V.V., Appel I., Development of the Aqua MODIS NDSI fractioal snow cover algorithm and validation results, IEEE Transactions on Geoscience and Remote Sensing, 2006, 44(7), pp. 1747-1756. DOI: 10.1109/TGRS.2006.876029.

[5] Klein A.G., Stroeve J., Development and validation of a snow albedo algorithm for MODIS instrument, Annals of Glaciology, 2002, 34, pp. 45-52. DOI: 10.3189/172756402781817662.

[6] Kumar Sujay V., Mocko David, Peters-Lidard Christa D., Tian Yudong, Multiscale Evaluation of the improvements in surface snow simulation through terrain adjustments to radiation, Hydrometeorology, 2013, 14, pp. 220-232. DOI: 10.1175/jhm-d-12-046.1.

[7] Kumar Sujay V., Peters-Lidard Christa D., Tian Yudong, Houser Paul R., Geiger James, Olden S., Lighty L., Eastman Joseph L., Doty B., Dirmeyer P., Adams J., Mitchell K., Wood E.F., Sheffield J., Land information system: an interoperable framework for high resolution land surface modeling, Environmental modeling \& software, 2006, 21(10), pp. 1402-1415. DOI: 10.1016/j.envsoft.2005.07.004.

[8] Hall Dorothy K., Riggs George A., Foster James L., Kumar Sujay V., Development and evaluation of a cloud-gap-filled MODIS daily snow-cover product, Remote Sensing of Environment, 2010, 114(3), pp. 496-503. DOI: $10.1016 /$ j.rse.2009.10.007.

[9] Kogan F.N. Application of vegetation index and brightness temperature for drought detection, Advances in Space Research, 1995, 15(11), pp. 91-100. DOI: 10.1016/0273-1177(95)00079-T.

[10] De Lannoy Gabrielle J.M., Reichle Rolf H., Arsenault Kristi R., Houser Paul R., Kumar Sujay, Verhoest Niko E.C., Pauwels Valentijn R.N., Multiscale assimilation of advanced microwave scanning radiometer-EOS snow water equivalent and moderate resolution imaging spectroradiometer snow cover fraction observations in northern Colorado, Water Resources Research, 2012, 48(1), DOI: 10.1029/2011WR010588. 